\title{
Secular trends in cardiovascular risk factors among women aged $45-54$ years in Gothenburg, Sweden, from 1980 to 2014
}

\author{
Carina U. Persson ${ }^{1,2^{*}}$ D , Anna-Clara Collén ${ }^{3,4}$, Annika Rosengren ${ }^{3,4}$, Zacharias Mandalenakis ${ }^{3,4}$, \\ Tatiana Zverkova Sandström ${ }^{3,4}$, Michael Fu ${ }^{3,4}$, Mikael Dellborg ${ }^{3,4}$, Saga Johansson ${ }^{3}$ and Per-Olof Hansson ${ }^{3,4}$
}

\begin{abstract}
Background: A declining trend in mean cholesterol levels and smoking has been observed in high-income western countries during the last few decades, whereas obesity rates have increased. Simultaneously, mortality from coronary heart disease has decreased. The aim of the present study was to determine whether the trends in cardiovascular risk factors have continued in successive cohorts of middle-aged women over a period of 34 years.

Methods: Six population-based, cross-sectional samples of women ( $n=2294)$ mean age: 49.8 years (range: $45-54)$, living in Gothenburg, Sweden, were investigated between 1980 and 2014.

Results: Body mass index (BMI) increased over time, with a mean BMl of $24.7 \mathrm{~kg} / \mathrm{m}^{2}$ in 1980 to $25.7 \mathrm{~kg} / \mathrm{m}^{2}$ in $2013-$ 2014 , corresponding to a weight gain of $4.5 \mathrm{~kg}$, together with an increase in the proportion of obese individuals $\left(\mathrm{BMl} \geq 30 \mathrm{~kg} / \mathrm{m}^{2}\right)$ from 10.4 to $16.6 \%(p=0.0012)$. The proportion of smokers and women with hypertension decreased from 34.5 to $12.8 \%(p=0.0006)$ and from 37.7 to $24.5 \%(p<0.0001)$ respectively. Mean total serum cholesterol levels decreased from 6.23 (SD 1.09) $\mathrm{mmol} / \mathrm{L}$ in 1980 to 5.43 (SD 0.98) mmol/L in 2013-2014 ( $p<0.0001$ ). Self-reported leisure time regular exercise increased from $7.8 \%$ in 1980 to $35.6 \%$ in $2013-2014(p<0.0001)$. For women born in 1963, the prevalence ratio of not having any of five major cardiovascular risk factors was 1.82 ( $95 \%$ confidence interval (Cl) 1.382.41), compared with women born in 1925-1934.

Conclusion: The trend towards increasing obesity, more leisure-time physical activity and less smoking remains, while the decrease in serum cholesterol appears to have abated.
\end{abstract}

Keywords: Epidemiology, Obesity, Physical activity, Population health

\section{Background}

Since the 1970s, declining mortality trends in coronary heart disease have been observed inside and outside Europe, $[1,2]$ due mainly to better treatment and improvements in cardiovascular risk factors, $[3,4]$

\footnotetext{
* Correspondence: carina.persson@neuro.gu.se

'Department of Clinical Neuroscience, Rehabilitation Medicine, Institute of Neuroscience and Physiology, Sahlgrenska Academy, University of Gothenburg, Gothenburg, Sweden

${ }^{2}$ Region Västra Götaland, Department of Physiotherapy, Sahlgrenska University Hospital/Östra, Gothenburg, Sweden

Full list of author information is available at the end of the article
}

predominantly lower smoking rates, serum cholesterol and blood pressure. While the incidence of fatal myocardial infarction has decreased in both sexes, some data suggest that the decline in non-fatal myocardial infarction may be less pronounced in middle-aged and younger women than in men of the same age [5]. Although risk factor patterns are improving and coronary heart disease mortality rates are decreasing in the western world, the opposite is occurring in the eastern parts of the world, such as China [6] and Eastern Europe [7].

C C The Author(s). 2020 Open Access This article is licensed under a Creative Commons Attribution 4.0 International License, which permits use, sharing, adaptation, distribution and reproduction in any medium or format, as long as you give appropriate credit to the original author(s) and the source, provide a link to the Creative Commons licence, and indicate if changes were made. The images or other third party material in this article are included in the article's Creative Commons licence, unless indicated otherwise in a credit line to the material. If material is not included in the article's Creative Commons licence and your intended use is not permitted by statutory regulation or exceeds the permitted use, you will need to obtain permission directly from the copyright holder. To view a copy of this licence, visit http://creativecommons.org/licenses/by/4.0/. The Creative Commons Public Domain Dedication waiver (http://creativecommons.org/publicdomain/zero/1.0/) applies to the data made available in this article, unless otherwise stated in a credit line to the data. 
In health promotion work, it is important for healthcare providers and society to be aware of changes in risk factors over time. Few studies have provided information on secular trends in cardiovascular risk factors over an extended period [8-12]. We have previously reported a decline in cardiovascular risk factors in five cohorts of middle-aged women over a 23-year period, demonstrating lower rates of smoking, decreasing total serum cholesterol levels, fewer women with hypertension and an increase in leisure-time physical activity over time [13]. On the other hand, rates of obesity, triglyceride levels and experience of permanent stress increased during this period [13]. The same secular trends in cardiovascular risk factor patterns were seen among middle-aged men from the same geographical area from the 1960s until 2013 [12].

The aim of the present study was to determine whether the trends in predefined cardiovascular risk factors, obesity, hypertension, hypercholesterolemia, diabetes or smoking among middle-aged women have been maintained over time, by adding a sixth cohort of randomly selected middle-aged women, living in the same geographical area, and investigated using the same methodology as for the previous five cohorts.

\section{Methods}

\section{Study population}

The study population comprised 2294 women from six randomly selected cohorts of middle-aged women, all living in the city of Gothenburg, Sweden, who, between 1980 and 2014, participated in investigations (Table 1). Data on cardiovascular and coronary heart disease risk factors were collected using standardised questionnaires and physical examinations.

Cohort 1 consists of a sample of women, born in 1925-1934 and aged 45-54 years when investigated between November 1979 and February 1981, from the Gothenburg BEDA study [14]. In this study, a random population sample of women living in the city of Gothenburg was invited to a screening examination of cardiovascular disease [14].

Cohorts 2, 3 and 4 consist of randomly sampled women aged 45 to 54 years participating in the WHO
MONICA project, GOT-MONICA, [15, 16] screened in 1985, 1990 and 1995.

Cohort 5 derives from "The study of men and women born in 1953" [17]. One third of all women born in 1953 and living in the city of Gothenburg were randomly selected and invited to a health examination at the age of 50 .

Secular trends in risk factor patterns in these five cohorts have previously been presented [13]. The new cohort (cohort 6) derives from "The study of men and women born in 1963" [18]. Every fifth woman born in 1963 and living in the city of Gothenburg was randomly selected and invited to participate in the study. The investigations were performed between October 2013 and April 2014 , with all participants at the age of 50 years [18].

\section{Data collection and examination procedures}

Data on smoking habits, leisure-time physical activity, mental stress, previous diseases and pharmacological treatments were obtained by questionnaires. Height was recorded to the nearest centimetre. Body weight was measured on a lever balance to the nearest $0.1 \mathrm{~kg}$ with the women barefoot and wearing light indoor clothing. Waist circumference was measured in $\mathrm{cm}$ at the level of the umbilicus. Body mass index (BMI, weight in $\mathrm{kg} /(\text { height in } \mathrm{m})^{2}$ ) was used as an indicator of overweight and obesity. Overweight was defined as a BMI of $25 \mathrm{~kg} / \mathrm{m}^{2}$ or higher, while obesity was defined as a BMI of $\geq 30 \mathrm{~kg} / \mathrm{m}^{2}$.

Blood pressure was measured, using a mercury manometer, in a seated position after at least 5 min' rest and before venpuncture. Hypertension was defined as systolic blood pressure of $>140 \mathrm{mmHg}$ and/or diastolic blood pressure of $>90 \mathrm{mmHg}$ and/or treatment with antihypertensive agents.

Blood samples were drawn from the antecubital vein. Analyses of total serum cholesterol and triglyceride measurements were determined according to standard laboratory procedures. In cohorts 1-5, all the women were investigated in the morning after an overnight fast. In Cohort 6, for practical reasons, almost one third of the women were investigated in the afternoon after at least $4 \mathrm{~h}$ of fasting.

The diagnosis of diabetes mellitus was self-reported in the questionnaire. The women were classified as never

Table 1 Participation rates in six cohorts of middle-aged women living in Gothenburg, Sweden

\begin{tabular}{llllll}
\hline Birth year & Year of examination & Age at examination, years & Number invited & Number examined & Participation rate (\%) \\
\hline $1925-1934$ & 1980 & $45-54$ & 754 & 618 & 82 \\
$1931-1940$ & 1985 & $45-54$ & 246 & 207 & 84 \\
$1936-1945$ & 1990 & $45-54$ & 291 & 218 & 75 \\
$1941-1950$ & 1995 & $45-54$ & 354 & 241 & 68 \\
1953 & $2003-2004$ & $50-51$ & 994 & 667 & 67 \\
1963 & $2013-2014$ & 50 & 645 & 343 & 53 \\
\hline
\end{tabular}


smokers, former smokers or current smokers. The category of current smokers includes women who had quit smoking less than 1 month before the investigation.

Leisure-time level was assessed using the SaltinGrimby Physical Activity Level Scale (SGPALS) [19]. The SGPALS is an ordinal scale comprising four response categories coded as: $1=$ sedentary (physically inactive); 2 = some light physical activity, such as walking, riding a bicycle and light gardening for at least $4 \mathrm{~h}$ a week; 3 = regular moderate physical activity for a minimum of $3 \mathrm{~h}$ a week and $4=$ regular hard physical training for competition sports. In the analyses, categories 3 and 4 were combined, due to the small number of women in category 4.

Mental stress was defined as feeling tense, irritable or filled with anxiety or having sleeping difficulties because of conditions at work or at home. The mental stress questionnaire comprises six response categories: $1=$ never experienced stress; 2 = one period of stress ever; $3=$ some periods of stress during the past 5 years; $4=$ several periods of stress during the past 5 years; $5=$ permanent stress during the past year and $6=$ permanent stress during the past 5 years. Permanent stress was defined by category 5 or 6 [20].

The study complies with the Declaration of Helsinki.

\section{Statistical methods}

The statistical analysis, data management and graphical presentation were conducted in SAS 9.3 (SAS Institute, Gary, North Caroline, USA). Each cohort was assigned a sequential number from 1 to 6 , related to the order of the year of birth. The descriptive results are presented as a mean (standard deviation) for continuous data and as a frequency (percentage) for categorical data. One-way ANOVA was used to compare group means and the Cochran-Mantel-Haenszel test was used to examine differences in proportions, when a linear association between study groups was hypothesised. Equality of proportions was assessed with the $\chi^{2}$ test. The presence of trends over time in dichotomous variables was assessed using the Cochran-Armitage Asymptotic test. The mean change across the study cohorts was tested by linear regression for continuous variables and by logistic regression for categorical data. The results are presented as parameter estimates (95\% $\mathrm{CI})$. Prevalence ratios (risk ratios) of the number of risk factors were calculated with Cohort 1 as reference. Cohorts 5 and 6 were then further compared as follows: $t$-test for mean values; Wilcoxon's non-parametric test for medians; the Mantel-Haenszel test for categorical and $\chi^{2}$ for dichotomous variables. The significance level was set at a $p$-value of $<0.05$.

\section{Results}

As shown in Table 1, the participation rates decreased, from over $80 \%$ in the first two cohorts, to $53 \%$ in the latest cohort. Table 2 shows anthropometric measurements, cardiovascular risk factors, physical activity levels and permanent stress in all six cohorts of women. From the first investigation in 1980 to the last in 2013-2014, the mean height and body weight increased by about two centimetres to $165.9 \mathrm{~cm} \mathrm{(} P$ for trend $<0.0001$ ) and $4.5 \mathrm{~kg}$ to $70.7 \mathrm{~kg}$ ( $P$ for trend < $0.0001)$ respectively. The mean waist circumference increased markedly; from $80.1 \mathrm{~cm}$ in 1985 to $88.4 \mathrm{~cm}$ in 2013-2014 (waist circumference was not measured in the first cohort). The proportion of obese women increased from 10.4 to $16.6 \%$ from 1980 to 2013 . Throughout the same period, there was a trend towards a lower prevalence of hypertension.

Mean serum cholesterol decreased from 6.23 (SD 1.09) $\mathrm{mmol} / \mathrm{L}$ in 1980 to 5.43 (SD 0.98) $\mathrm{mmol} / \mathrm{L}$ in 2013-2014. The proportion of women with self-reported diabetes mellitus was low, ranging between 1.0 and $2.4 \%$, without any significant change over time. The decrease in smoking has continued and, in the latest cohort, $13 \%$ of the women were current smokers, in contrast to $34.5 \%$ registered in the first cohort. High-intensity leisure-time physical activity has steadily increased over the decades. In the latest cohort, $35.6 \%$ of the women reported being physically active at an intensive level on a regular basis. Simultaneously, the proportion of women with a sedentary lifestyle declined from 23.5 to $10.5 \%$. Self-reported permanent stress has increased over the years, but, in the latest cohort, women born in 1963, no further increase was found compared with women born in 1953.

When comparing only the latest two cohorts, a significant increase was observed in waist circumference, systolic blood pressure and physical activity during leisure time, while there was a significant decrease in striglycerides and the number of smokers (Table 2).

Table 3 shows the prevalence ratios (PRs) for having none and one to four or five of the predefined cardiovascular risk factors (body mass index $\geq 25$, hypertension, serum cholesterol $>5 \mathrm{mmol} / \mathrm{L}$, diabetes and smoking), with women born in 1925-1934 (Cohort 1) as a reference. For women born in 1963, the PR for not having any of the predefined risk factors was 1.82 (95\% confidence interval (CI) 1.38-2.41), while the PR for having four or five risk factors was 0.75 (95\% CI 0.64-0.88). The percentage of participants with $0,1,2,3$ or $4-5$ of the predefined risk factors is presented in Fig. 1.

The women who reported a regular/athletic physical activity level did not increase their mean BMI over time and nor did sedentary women. However, in those reporting moderate leisure-time physical activity levels, BMI increased significantly in successive cohorts (Fig. 2).

\section{Discussion}

In the latest studied cohort, the trend towards increasing obesity, more leisure-time physical activity and less 


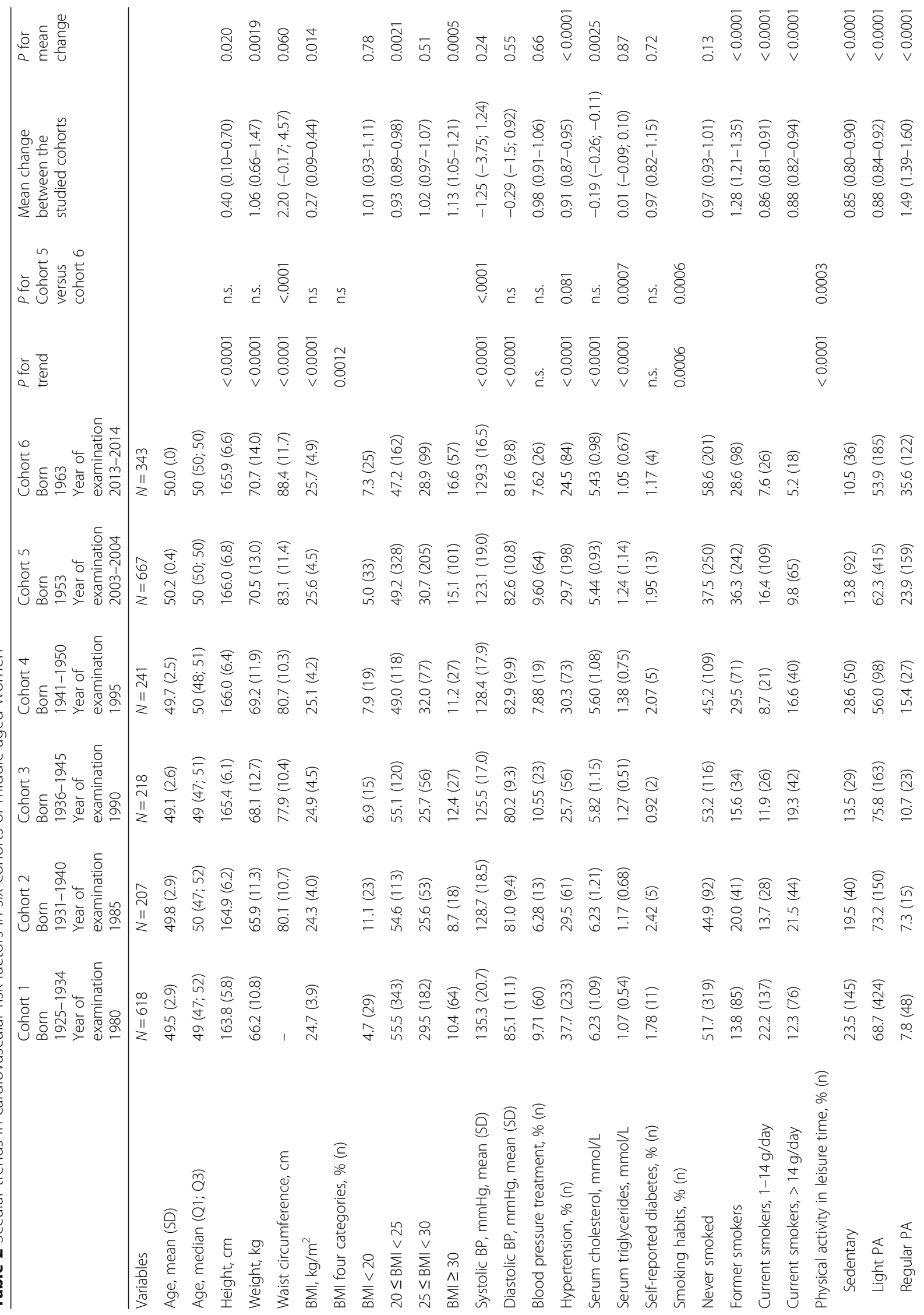




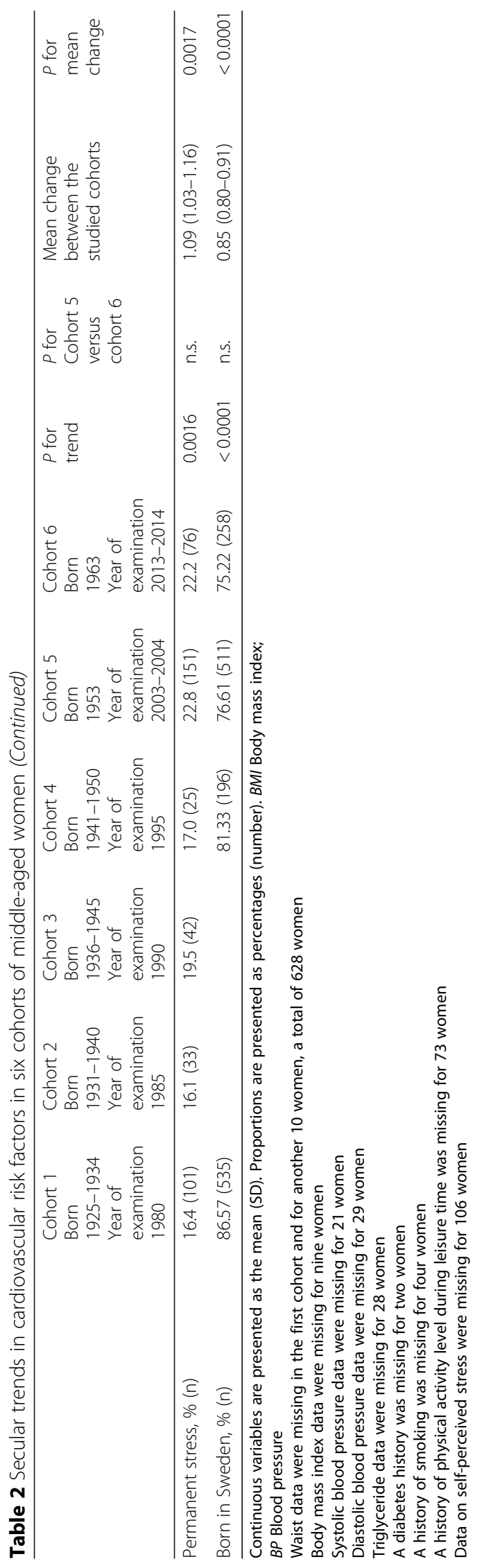


Table 3 Prevalence ratios (PRs) for the number of predefined cardiovascular risk factors in six cohorts of middle-aged women

\begin{tabular}{|c|c|c|c|c|c|c|c|c|c|c|c|c|c|c|c|}
\hline \multirow[b]{2}{*}{ Year of birth } & \multicolumn{3}{|c|}{ O risk factor } & \multicolumn{3}{|c|}{1 risk factor } & \multicolumn{3}{|c|}{2 risk factors } & \multicolumn{3}{|c|}{3 risk factors } & \multicolumn{3}{|c|}{4 risk factors } \\
\hline & $\mathrm{n}$ & PR & $95 \% \mathrm{Cl}$ & $\mathrm{n}$ & $P R$ & $95 \% \mathrm{Cl}$ & $\mathrm{n}$ & $P R$ & $95 \% \mathrm{Cl}$ & $\bar{n}$ & PR & $95 \% \mathrm{Cl}$ & $\mathrm{n}$ & PR & $95 \% \mathrm{Cl}$ \\
\hline 1925-1934 & 32 & 1.00 & & 164 & 1.00 & & 229 & 1.00 & & 166 & 1.00 & & 27 & 1.00 & \\
\hline 1931-1940 & 15 & 1.11 & $0.91-1.35$ & 60 & 1.03 & $0.94-1.13$ & 85 & 1.04 & $0.96-1.13$ & 38 & 0.89 & $0.82-0.97$ & 9 & 1.00 & $0.82-1.21$ \\
\hline 1936-1945 & 22 & 1.26 & $1.01-1.58$ & 72 & 1.09 & $0.99-1.20$ & 79 & 0.99 & $0.91-1.08$ & 38 & 0.88 & $0.81-0.95$ & 7 & 0.93 & $0.78-1.11$ \\
\hline 1941-1950 & 34 & 1.52 & $1.18-1.96$ & 74 & 1.06 & $0.96-1.17$ & 72 & 0.92 & $0.84-1.00$ & 55 & 0.94 & $0.86-1.03$ & 6 & 0.87 & $0.74-1.03$ \\
\hline 1953 & 96 & 2.03 & $1.49-2.75$ & 208 & 1.13 & $0.99-1.29$ & 206 & 0.87 & $0.77-0.98$ & 130 & 0.81 & $0.72-0.92$ & 27 & 0.96 & $0.73-1.26$ \\
\hline 1963 & 55 & 1.82 & $1.38-2.41$ & 131 & 1.23 & $1.09-1.37$ & 101 & 0.89 & $0.81-0.98$ & 51 & 0.79 & $0.72-0.87$ & 5 & 0.75 & $0.64-0.88$ \\
\hline
\end{tabular}

Cardiovascular risk factors: body mass index $\geq 25$, hypertension, serum cholesterol $>5 \mathrm{mmol} / \mathrm{L}$, diabetes and smoking

Women born in 1925-1934 served as the reference group. In all, there were 36 women with missing data. Cl Confidence interval; $P R$ Prevalence ratio

smoking remains, while the decrease in total serum cholesterol appears to have abated, with essentially identical mean levels in the two last cohorts. Since 1980, the prevalence ratio for not having any of the five predefined cardiovascular risk factors was more than $80 \%$ higher, while the prevalence ratio for having four or five of these risk factors decreased by $25 \%$. These results are consistent with previously reported secular trends for men in the same region [12].

The pattern of reduced smoking and increased BMI is also similar to the results of the MONICA study from northern Sweden [9]. Likewise, in line with our results, an upward trend for regular exercise or athletic training during leisure time and a decreasing trend for smoking, blood pressure and cholesterol were observed in crosssectional surveys of 40- to 42-year-old Norwegians from 1975 to 2010 [21].

In all six cohorts, the prevalence of diabetes mellitus was low, reflecting the general, comparatively low prevalence in the Swedish population [22]. The lack of an increase in diabetes, in spite of increasing obesity, has also been documented in some other European countries; the reason for this is not clear [23].

Even a minor increase in blood pressure levels in a large population may lead to marked increases in the burden of cardiovascular disease in the community [24]. In the current study, however, the blood pressure levels decreased between the first and the second cohort and have since then been comparatively stable. Due to the strong correlation between obesity and hypertension, increasing blood pressure levels and the prevalence of hypertension in the population are likely to occur in the future and may lead to an increase in cardiovascular diseases, especially stroke. A decreasing trend in the incidence of ischemic stroke in Sweden has been documented, however, with a worrying trend towards an increasing incidence in the young [25].

The trend towards an increasing level of leisure-time physical activity has also been observed in other countries such as Finland, Scotland, the USA, Canada, Taiwan and Australia [26]. A cross-sectional study of 2605 middle-aged Swiss men and women showed that a

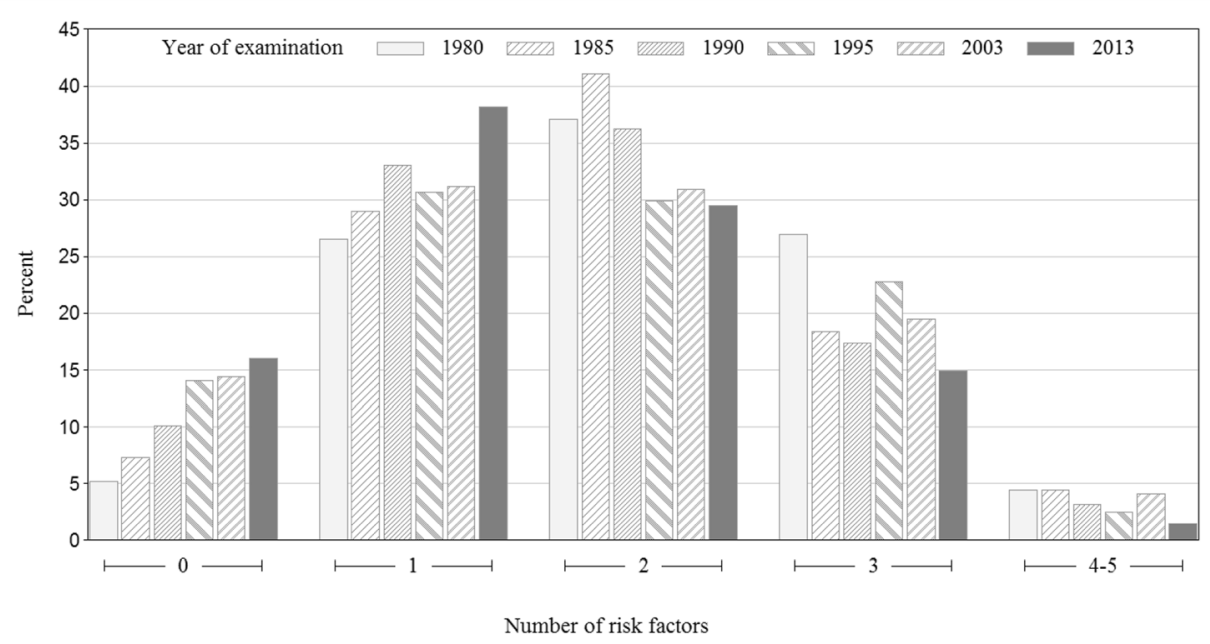

Fig. 1 Percentage of participants with 0, 1, 2, 3 or 4-5 of 5 predefined cardiovascular risk factors in six cohorts of middle-aged women examined in: 1980, 1985, 1990, 1995, 2003-2004 and 2013-2014 


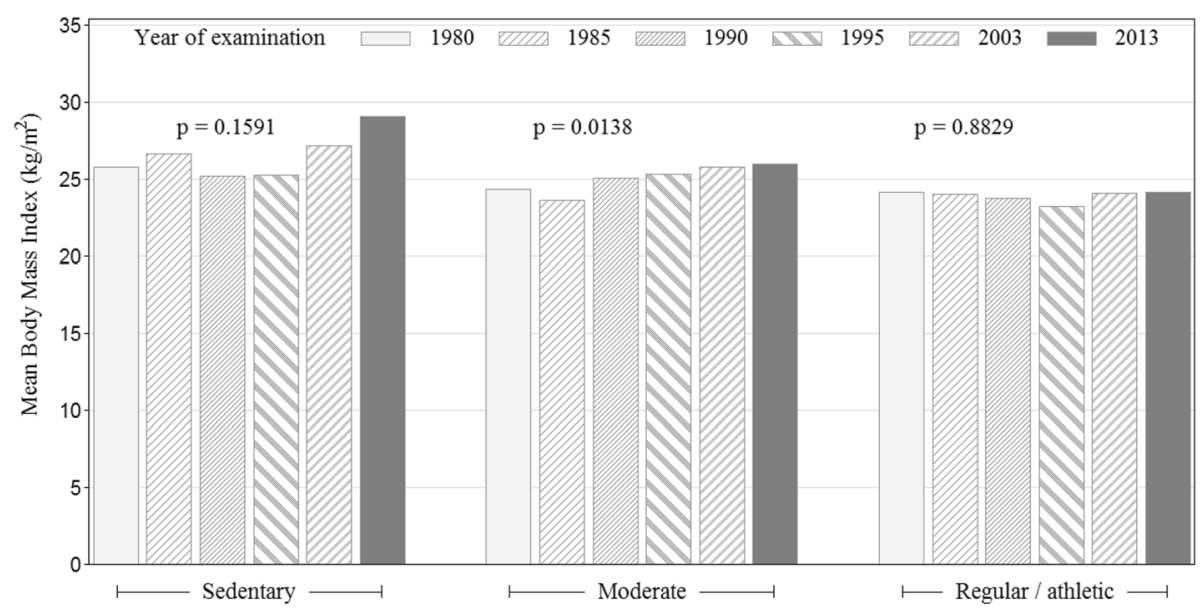

Physical activity during leisure time

Fig. 2 Mean body mass index (MBI) (X-axis) in six cohorts of middle-aged women with different levels of physical activity during leisure time (Y-axis)

high level of physical activity was associated with a favourable cardiovascular risk profile. This was seen, even if the activity was only concentrated at weekends or was concomitant with an otherwise highly sedentary lifestyle [27].

In spite of the positive trend towards fewer smokers, they still account for $13 \%$ of the population. People who smoke often have other cardiovascular risk factors and a study of Norwegian adults showed that smokers were more likely to have low leisure-time physical activity levels compared with non-smokers [28].

Mental stress may act as a trigger for major cardiac events and influence the prognosis of cardiovascular disease and the progress of stress cardiomyopathy [29]. The same questionnaire for mental stress was used in a prior study of 6935 men aged 47 to 54 years at baseline without previous myocardial infarction [20]. That study found that permanent stress predicted non-fatal myocardial infarction or death from coronary artery disease during a mean follow-up of 11.8 years. In another study, based on a 37-year follow-up of middle-aged women in Gothenburg, the perception of high mental stress was associated with smoking and thereby a higher cardiovascular risk [30].

The trend towards declining serum cholesterol levels over time did not continue between 2003 and 20132014. The same trend was observed among Swedish men from the same geographical area [12]. In the Swedish Västerbotten County Study, however, the investigators found a trend towards increasing serum cholesterol levels, believed to be due to a higher consumption of saturated fat [11].

The main strength of this study is the well-defined population samples of women living in the same geographical area and examined at the same age with the same methods over three decades.

However, there are also some potential limitations to be considered. First, the cohort sizes were relatively small. Second, there is a risk of selection bias with decreasing participation rates, as participating women may differ from non-participating women. Participants in population studies tend to have a higher socioeconomic status and to be healthier than non-participants [31]. Accordingly, there is a risk of overestimating the positive changes that are seen, in addition to underestimating the adverse changes for corresponding reasons. The reduced participation rates in population studies are a well-known problem when comparing secular changes [32]. Third, the use of the Saltin-Grimby scale might have biased the results due to social desirability and recall bias, compared with measurements that are more objective [33]. The fact that several variables, such as smoking, diabetes, mental stress and physical activity, were self-reported can cause validity problems. In cohort 6 , almost one third of the women were investigated in the afternoon after at least $4 \mathrm{~h}$ of fasting. The shorter period of fasting may influence the levels of triglycerides, while only a minor influence on serumcholesterol levels is related to fasting [34]. The low prevalence of diabetes may be due to self-report bias related to diabetes status. In addition, the results cannot be generalised to other ages, parts of the world or to men. Cardiovascular risk factors are constantly changing as lifestyles are modified. As a result, new studies and updated data are needed from different parts of the world.

\section{Conclusions}

The trend towards increasing obesity, more leisure-time physical activity and less smoking remains, while the 
decrease in serum cholesterol appears to have abated. Compared with 1980, the prevalence ratio for not having any of the five major cardiovascular risk factors was almost twice as high in 2013-2014. In spite of this, with one in seven women still smoking, one in six obese and a markedly increasing waist circumference, continuing efforts are necessary to improve health literacy and lifestyle changes, particularly in relation to preventing obesity.

\section{Abbreviations}

PR: Prevalence ratio; SD: Standard deviation; BMI: Body mass index

\section{Acknowledgements}

The authors are very grateful to all the participating women and to the staff who contributed to the studies over the years.

\section{Authors' contributions}

$\mathrm{AR}, \mathrm{SJ}$, and $\mathrm{POH}$ contributed to the conception or design of the examinations. TZS made the statistical analysis. All the authors (CUP, ACC, AR, $\mathrm{ZM}$, TZS, MF, MD, SJ and POH) contributed to the acquisition, analysis or interpretation of the data. CUP drafted the manuscript. All the authors revised the manuscript critically and agreed to be accountable for all aspects of the work, thereby ensuring integrity and accuracy. All the authors read and approved the final manuscript.

\section{Funding}

The authors disclose the receipt of the following financial support for the research, authorship and/or publication of this paper. The study was financed by grants from Anna Ahrenberg's Foundation and from the Swedish state under the agreement between the Swedish government and the county councils: the ALF agreement (ALFGBG-721351), AFA insurance, the Swedish Heart and Lung Foundation and the Swedish Research Council. Open access funding provided by University of Gothenburg.

\section{Availability of data and materials}

The datasets analysed during the current study are not publicly available, due to the protection of personal data, but they are available from one of the authors $(\mathrm{POH})$ in response to a reasonable request.

\section{Ethics approval and consent to participate}

The Ethical Committee of Gothenburg approved the study protocol (2013/ 649) on 25 September 2013. Oral and written informed consent was given by all participants prior to the study.

\section{Consent for publication}

N.A.

\section{Competing interests}

The authors declare no potential conflicts of interest.

\begin{abstract}
Author details
'Department of Clinical Neuroscience, Rehabilitation Medicine, Institute of Neuroscience and Physiology, Sahlgrenska Academy, University of Gothenburg, Gothenburg, Sweden. ${ }^{2}$ Region Västra Götaland, Department of Physiotherapy, Sahlgrenska University Hospital/Östra, Gothenburg, Sweden. ${ }^{3}$ Department of Molecular and Clinical Medicine, Institute of Medicine, Sahlgrenska Academy, University of Gothenburg, Gothenburg, Sweden. ${ }^{4}$ Region Västra Götaland, Department of Medicine Geriatric and Emergency, Sahlgrenska University Hospital, Gothenburg, Sweden.
\end{abstract}

Received: 18 April 2019 Accepted: 12 June 2020

Published online: 01 July 2020

\section{References}

1. Wilhelmsen L, Rosengren A, Johansson S, Lappas G. Coronary heart disease attack rate, incidence and mortality 1975-1994 in Goteborg, Sweden. Eur Heart J. 1997;18(4):572-81.
2. Levi F, Chatenoud L, Bertuccio P, Lucchini F, Negri E, La Vecchia C. Mortality from cardiovascular and cerebrovascular diseases in Europe and other areas of the world: an update. Eur J Cardiovasc Prev Rehabil. 2009;16(3):333-50.

3. Bjorck L, Rosengren A, Bennett K, Lappas G, Capewell S. Modelling the decreasing coronary heart disease mortality in Sweden between 1986 and 2002. Eur Heart J. 2009:30(9):1046-56.

4. Mannsverk J, Wilsgaard T, Mathiesen EB, Lochen ML, Rasmussen K, Thelle DS, Njolstad I, Hopstock LA, Bonaa KH. Trends in modifiable risk factors are associated with declining incidence of hospitalized and nonhospitalized acute coronary heart disease in a population. Circulation. 2016;133(1):74-81.

5. Rosengren A, Thelle DS, Koster M, Rosen M. Changing sex ratio in acute coronary heart disease: data from Swedish national registers 1984-99. J Intern Med. 2003;253(3):301-10.

6. Ren $Y$, Zhang M, Luo X, Zhao J, Yin L, Pang C, Feng T, Wang S, Wang B, Zhang $\mathrm{H}$, et al. Secular trend of the leading causes of death in China from 2003 to 2013. Afr Health Sci. 2017;17(2):532-7.

7. Hartley A, Marshall DC, Salciccioli JD, Sikkel MB, Maruthappu M, Shalhoub J. Trends in mortality from ischemic heart disease and cerebrovascular disease in Europe: 1980 to 2009. Circulation. 2016;133(20):1916-26.

8. Borodulin $\mathrm{K}$, Vartiainen E, Peltonen M, Jousilahti P, Juolevi A, Laatikainen T, Mannisto S, Salomaa V, Sundvall J, Puska P. Forty-year trends in cardiovascular risk factors in Finland. Eur J Pub Health. 2015;25(3):539-46.

9. Eriksson $M$, Holmgren $L$, Janlert $U$, Jansson $J H$, Lundblad $D$, Stegmayr $B$, Soderberg $\mathrm{S}$, Eliasson M. Large improvements in major cardiovascular risk factors in the population of northern Sweden: the MONICA study 19862009. J Intern Med. 2011;269(2):219-31.

10. Gregg EW, Cheng YJ, Cadwell BL, Imperatore G, Williams DE, Flegal KM, Narayan KM, Williamson DF. Secular trends in cardiovascular disease risk factors according to body mass index in US adults. Jama. 2005;293(15): 1868-74.

11. $\mathrm{Ng} \mathrm{N}$, Johnson $\mathrm{O}$, Lindahl B, Norberg M. A reversal of decreasing trends in population cholesterol levels in Vasterbotten County, Sweden. Glob Health Action. 2012;5. https://doi.org/10.3402/gha.v5i0.10367 Epub 2012 Mar 23.

12. Zhong Y, Rosengren A, Fu M, Welin L, Welin C, Caidahl K, Mandalenakis Z, Dellborg M, Svardsudd K, Hansson PO. Secular changes in cardiovascular risk factors in Swedish 50-year-old men over a 50-year period: the study of men born in 1913, 1923, 1933, 1943, 1953 and 1963. Eur J Prev Cardiol. 2017;24(6):612-20.

13. Johansson S, Wilhelmsen L, Welin C, Eriksson H, Welin L, Rosengren A. Obesity, smoking and secular trends in cardiovascular risk factors in middleaged women: data from population studies in Goteborg from 1980 to 2003. J Intern Med. 2010:268(6):594-603.

14. Rosengren A, Wilhelmsen L, Lappas G, Johansson S. Body mass index, coronary heart disease and stroke in Swedish women. A prospective 19-year follow-up in the BEDA study. Eur J Cardiovasc Prev Rehabil. 2003;10(6):443-50.

15. Wilhelmsen L, Johansson S, Rosengren A, Wallin I, Dotevall A, Lappas G. Risk factors for cardiovascular disease during the period 1985-1995 In Goteborg, Sweden. The GOT-MONICA project. J Intern Med. 1997;242(3):199-211.

16. Kuulasmaa K, Tunstall-Pedoe H, Dobson A, Fortmann S, Sans S, Tolonen H, Evans A, Ferrario M, Tuomilehto J. Estimation of contribution of changes in classic risk factors to trends in coronary-event rates across the WHO MONICA Project populations. Lancet (London, England). 2000;355(9205): 675-87.

17. Welin L, Adlerberth A, Caidahl K, Eriksson H, Hansson PO, Johansson S, Rosengren A, Svardsudd K, Welin C, Wilhelmsen L. Prevalence of cardiovascular risk factors and the metabolic syndrome in middle-aged men and women in Gothenburg, Sweden. BMC Public Health. 2008;8:403. https:// doi.org/10.1186/1471-2458-8-403.

18. Persson $C E$, Rothenberg $E$, Hansson PO, Welin C, Strandhagen E: Cardiovascular risk factors in relation to dietary patterns in 50-year-old men and women: a feasibility study of a short FFQ. Public Health Nutr 2019, 22(4):645-653. doi: https://doi.org/10.1017/S1368980018002264. Epub 2018 Sep 14. 2018:1-9.

19. Saltin B, Grimby G. Physiological analysis of middle-aged and old former athletes. Comparison with still active athletes of the same ages. Circulation. 1968:38(6):1104-15.

20. Rosengren A, Tibblin G, Wilhelmsen L. Self-perceived psychological stress and incidence of coronary artery disease in middle-aged men. Am J Cardiol. 1991;68(11):1171-5.

21. Solbraa AK, Holme IM, Graff-Iversen S, Resaland GK, Aadland E, Anderssen SA. Physical activity and cardiovascular risk factors in a 40- to 42-year-old 
rural Norwegian population from 1975-2010: repeated cross-sectional surveys. BMC Public Health. 2014;14:569. https://doi.org/10.1186/1471-245814-569.

22. NCD Risk Factor Collaboration (NCD-RisC). Effects of diabetes definition on global surveillance of diabetes prevalence and diagnosis: a pooled analysis of 96 population-based studies with 331,288 participants. Lancet Diabetes Endocrinol. 2015;3(8):624-37.

23. Rosengren A. Cardiovascular disease in diabetes type 2: current concepts. Intern Med. 2018;284(3):240-53. https://doi.org/10.1111/joim.12804 Epub $2018 \mathrm{Jul} 18$

24. Lewington S, Clarke R, Qizilbash N, Peto R, Collins R. Age-specific relevance of usual blood pressure to vascular mortality: a meta-analysis of individual data for one million adults in 61 prospective studies. Lancet (London, England). 2002;360(9349):1903-13.

25. Rosengren A, Giang KW, Lappas G, Jern C, Toren K, Bjorck L. Twenty-fouryear trends in the incidence of ischemic stroke in Sweden from 1987 to 2010. Stroke. 2013;44(9):2388-93.

26. Knuth AG, Hallal PC. Temporal trends in physical activity: a systematic review. J Phys Act Health. 2009;6(5):548-59.

27. Gubelmann C, Antiochos P, Vollenweider P, Marques-Vidal P. Association of activity behaviours and patterns with cardiovascular risk factors in Swiss middle-aged adults: the CoLaus study. Prev Med Rep. 2018;11:31-6.

28. Morseth $B$, Jacobsen BK, Emaus N, Wilsgaard T, Jorgensen L. Secular trends and correlates of physical activity: the Tromso study 1979-2008. BMC Public Health. 2016;16(1):1215.

29. Steptoe A, Kivimaki M. Stress and cardiovascular disease: an update on current knowledge. Annu Rev Public Health. 2013;34:337-54.

30. Hange D, Mehlig K, Lissner L, Guo X, Bengtsson C, Skoog I, Bjorkelund C. Perceived mental stress in women associated with psychosomatic symptoms, but not mortality: observations from the population study of women in Gothenburg, Sweden. Int J Gen Med. 2013;6:307-15.

31. Harald K, Salomaa V, Jousilahti P, Koskinen S, Vartiainen E. Non-participation and mortality in different socioeconomic groups: the FINRISK population surveys in 1972-92. J Epidemiol Community Health. 2007;61(5):449-54.

32. Morton LM, Cahill J, Hartge P. Reporting participation in epidemiologic studies: a survey of practice. Am J Epidemiol. 2006;163(3):197-203.

33. Warren JM, Ekelund U, Besson H, Mezzani A, Geladas N, Vanhees L. Assessment of physical activity - a review of methodologies with reference to epidemiological research: a report of the exercise physiology section of the European association of cardiovascular prevention and rehabilitation. Eur J Cardiovasc Prev Rehabil. 2010;17(2):127-39.

34. Schaefer EJ, Audelin MC, McNamara JR, Shah PK, Tayler T, Daly JA, Augustin $J \mathrm{~L}$, Seman $\amalg$, Rubenstein JJ. Comparison of fasting and postprandial plasma lipoproteins in subjects with and without coronary heart disease. Am J Cardiol. 2001;88(10):1129-33.

\section{Publisher's Note}

Springer Nature remains neutral with regard to jurisdictional claims in published maps and institutional affiliations.

Ready to submit your research? Choose BMC and benefit from:

- fast, convenient online submission

- thorough peer review by experienced researchers in your field

- rapid publication on acceptance

- support for research data, including large and complex data types

- gold Open Access which fosters wider collaboration and increased citations

- maximum visibility for your research: over $100 \mathrm{M}$ website views per year

At BMC, research is always in progress.

Learn more biomedcentral.com/submissions 